\title{
Electronmicroscopic studies on the location of salmonella proliferation in the murine spleen
}

\author{
XIU-MEI WANG, F. R. LIN, H. S. HSU," V. R. MUMAW' and IRENE NAKONECZNAt \\ Department of Microbiology and Immunology and + Department of Pathology, Medical College of Virginia, \\ Virginia Commonwealth University, Richmond, Virginia 23298, USA
}

\begin{abstract}
Summary. Highly susceptible inbred male C57BL/6 mice were infected intraperitoneally with $2 \times 10^{7} \mathrm{cfu}$ of a virulent Salmonella typhimurium strain. Tissue sections were taken from the spleen 2 and 3 days after infection for examination by electronmicroscopy. Rapid infiltration of polymorphs and macrophages was evident at the site of infection. These inflammatory phagocytes displayed avid destructive action against ingested bacteria. Bacterial multiplication occurred primarily in extracellular locations within sinusoids or in lesions containing disintegrating host cells.
\end{abstract}

\section{Introduction}

We have demonstrated by electronmicroscopy the effective destruction of the pathogen within inflammatory phagocytes in the peritoneal cavity of mice challenged with virulent Salmonella typhimurium (Guo et al., 1986a and $b$ ). The presence of specific antiserum significantly enhances the phagocytic activity of host cells, but their capacity to digest the intracellular bacteria appears unchanged (Guo et al., 1986b). Because the intracellular environment of the inflammatory cells is evidently hostile to pathogenic salmonellae, it was argued that these organisms are unlikely to be facultative intracellular parasites, as they have traditionally been regarded (Collins, 1974). Their ability to propagate rapidly in host tissues during infection must, therefore, be relegated primarily to extracellular locations as observed in the peritoneal cavity of infected mice (Guo et al., 1986a). In a continuing effort to identify the site of bacterial proliferation in the reticuloendothelial system (RES) in murine salmonellosis, the present investigation examines the lesions in the spleen at an early stage of infection.

\section{Materials and methods}

\section{Bacterial culture}

A virulent strain of Salmonella typhimurium, SR-11, was grown in Tryptic Soy Broth (TSB; Difco) for $6 \mathrm{~h}$ at

Received 16 Feb. 1987; accepted 22 Apr. 1987.

*Correspondence and requests for offprints should be sent to Dr Hsu. $37^{\circ}$ in a drum rotating at $25 \mathrm{rpm}$. The culture was then washed in saline as described previously (Hsu and Radcliffe, 1968). The optically standardised bacterial suspension contained $c .2 \times 10^{12} \mathrm{cfu} / \mathrm{L}$.

\section{Mice}

Male inbred C57BL/6 mice 6-8 weeks old were purchased from Charles River Breeding Laboratory (Stone Ridge, NY, USA) and housed in the Central Animal Care Facility of the Medical College of Virginia for at least one week before being used.

\section{Infection of mice and sampling of tissues}

In each experiment, 10-20 mice were infected with an intraperitoneal (ip) injection of $c .2 \times 10^{7}$ cfu of $S$. typhimurium. On the second and the third days after infection, two or three mice were killed in a chloroform jar and their spleens rapidly removed. Samples were dissected from different areas of the spleen and placed in drops of glutaraldehyde $4 \% \mathrm{v} / \mathrm{v}$ in $0 \cdot 1 \mathrm{M}$ sodium cacodylate

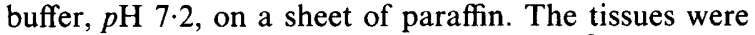
then minced into cubes of about $1 \mathrm{~mm}^{3}$ each and transferred into vials containing the same fixative.

\section{Preparation of tissue specimens for electronmicroscopy}

The glutaraldehyde-fixed tissues were post-fixed with osmium tetroxide $1 \%$ for $1 \mathrm{~h}$ at room temperature. After dehydration with increasing concentrations of ethanol, they were embedded in Polybed epoxy resin (Polysciences, Inc., Warrington, PA, USA). Thick sections (1-2 $\mu \mathrm{m})$ were stained with toluidine blue for light microscopy. Ultrathin 
sections $(50-100 \mathrm{~nm})$ were mounted on 200 -mesh copper grids and stained with uranyl acetate and Reynold's lead citrate before examination in a Hitachi HS-8 electronmicroscope.

\section{Results}

\section{Effect of bacterial infection}

The C57BL/6 mice were highly susceptible to challenge by $S$. typhimurium. The relatively large infective dose of $2 \times 10^{7}$ cfu given ip was intended to disseminate the pathogens rapidly into the RES and usually led to a death within 2-4 days. When the mice were killed on the second or the third day, splenomegaly was conspicuous. Minute lesions could be seen in the liver and spleen of some of the animals by the third day.

\section{Fate of salmonellae within polymorphs and macrophages in spleen}

In electronmicroscopy, viability of bacteria in host tissues is assessed on the basis of morphological integrity. In a previous publication (Guo et al., 1986a), two possible sequences of intracellular destruction of salmonellae were described. Bacterial degeneration begins either with central vacuolation and peripheral condensation of cytoplasmic granules, followed by disruption of bacterial envelope, or with peripheral compression of bacterial surface, early disruption of bacterial envelope and diffuse condensation of cytoplasmic granules.

In the present study, tissue specimens were taken from 17 infected mice in seven different experiments and examined by electronmicroscopy. Polymorphs and macrophages were readily seen at the site of infection in both the red and the white pulp of spleen. Intracellular bacteria underwent degenerative changes through either one of the sequences of events described above. Fig. 1 shows samples of polymorphs with ingested bacteria on the second day after infection. One of them (fig. 1A) contained at least six or seven bacteria within its phagolysosome in this plane of section. Most of the bacteria displayed extensive central vacuolation and peripheral condensation of cytoplasmic granules, while the structure of two of them had become barely recognisable (arrow). The phagolysosome also was full of digestive debris at this stage. In fig. 1B, one of the two adjacent polymorphs displays intracellular bacteria undergoing deterioration either by central vacuolation (open arrow) or by peripheral compression (arrows). The polymorph (P) in fig. 1C harboured several bacteria at various stages of destruction, from two apparently morphologically intact organisms (arrows) to some barely recognisable remains (open arrow). Another group of degenerating bacteria was enclosed within the phagocytic vacuole (arrowheads) of another phagocyte whose nucleus was not included in this plane of section.

Fig. 2 depicts four macrophages with intracellular bacteria. The macrophage on the second day after infection (fig. 2A) showed one phagolysosome containing at least five bacteria with extensive central vacuolation and peripheral cytoplasmic granulation. Another damaged organism (arrow)
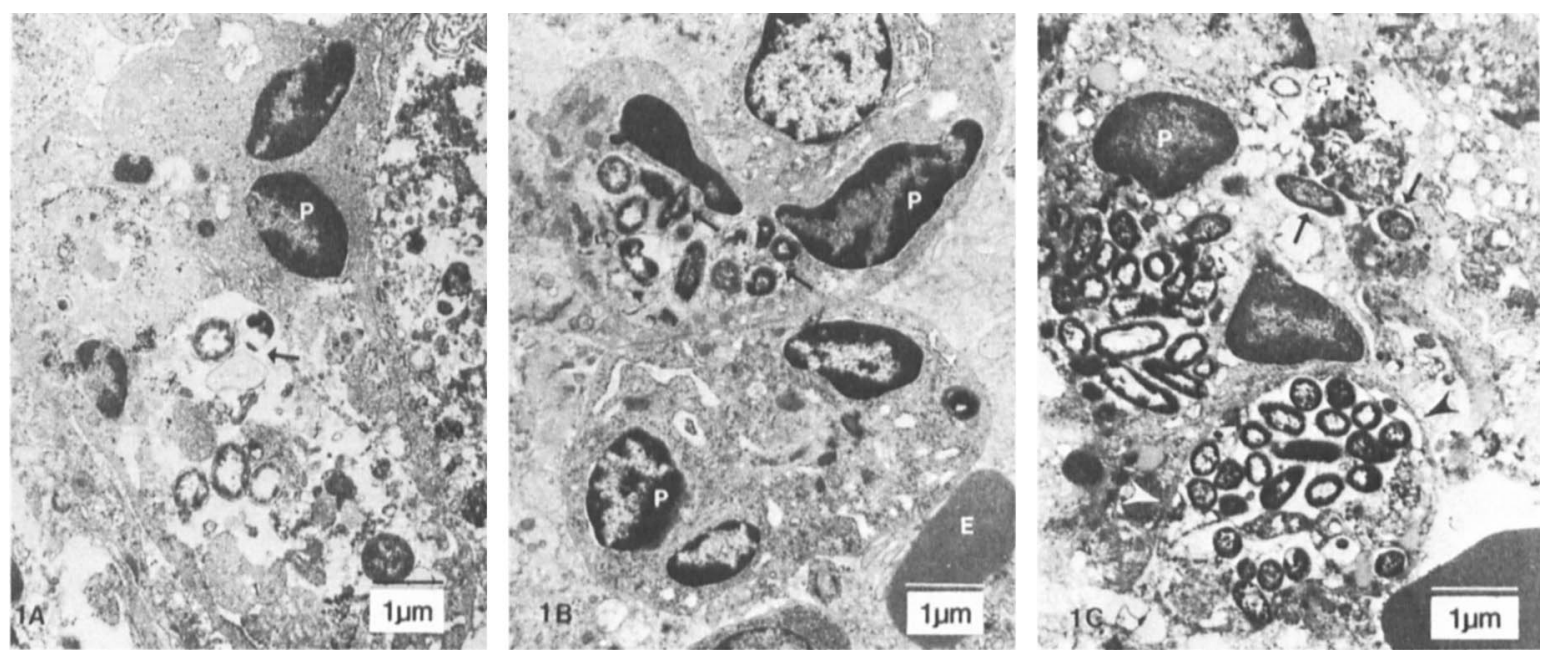

Fig. 1. Polymorphs with ingested bacteria 2 days after infection. $\mathbf{P}=$ nucleus; $E=$ erythrocyte. Magnifications: (A) 11000 ; (B) $13500 ;$ (C) 13600 . 

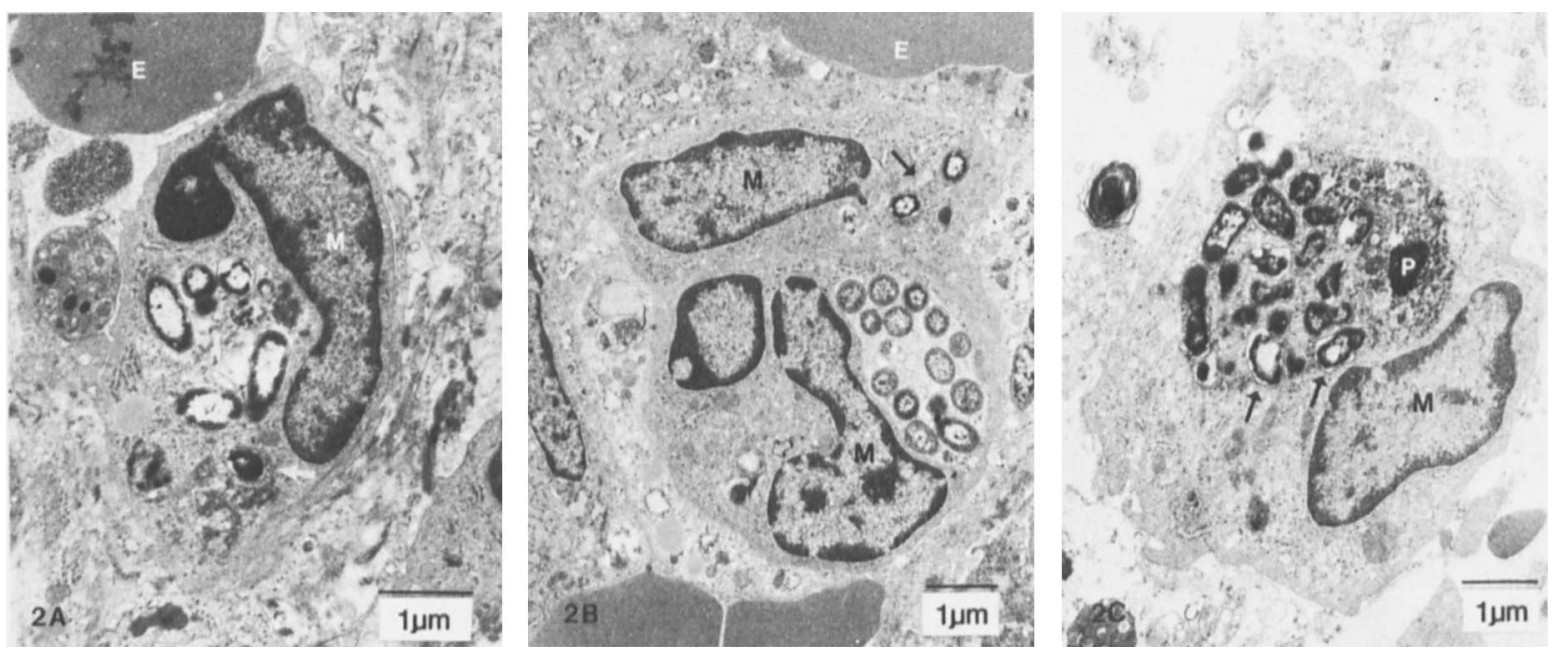

Fig. 2. Macrophages with ingested bacteria 2 and 3 days after infection. $\mathbf{M}=$ nucleus of macrophage; $\mathbf{P}=$ nucleus of polymorph. Magnifications: (A) 15500 ; (B) 12300 ; (C) 12400.

was in the midst of another area of phagocytic debris. In the two adjacent macrophages from an animal killed on the third day (fig. 2B), one shows two damaged bacteria (arrow) apparently in direct contact with the cytoplasm of the host cell. The other displays several organisms in transverse sections within a phagolysosome. Most of them appeared morphologically intact at this time. In the same macrophage, another damaged bacterium (open arrow) is seen in direct contact with its cytoplasm. The macrophage in fig. $2 \mathrm{C}$, from an animal killed on the third day had phagocytosed a polymorph with a pyknotic nucleus (P). The polymorph had in turn ingested a large number of bacteria, all of which manifested some forms of degenerative changes. The bacterial envelopes in some of these organisms (arrows) had separated from their cytoplasmic granules.

\section{Extracellular proliferation of salmonellae in spleen}

In contrast to the killing of bacteria within inflammatory phagocytes, the increase of bacterial population during infection could be discerned in the extracellular locations of the spleen. Fig. 3 shows an accumulation of morphologically intact bacteria in the sinusoid of the spleen on the third day after infection. Their direct contact with the surrounding erythrocytes (E) confirms that they were extracellular. In fig. 4, a large number of pathogens was present adjacent to a disintegrating polymorph whose pyknotic nucleus (P) could be seen. The morphological integrity and cellular divisions (arrows) exhibited by these organisms suggest that surviving organisms released from the lysed polymorph were viable and actively replicating on the second day. The prominence of erythrocytes in this area indicates that the lesion was present in the red pulp of the spleen. On the third day, as seen in fig. 5 , morphologically intact bacteria were scattered in a lesion with diffuse cellular debris, degenerative nuclei $(\mathrm{N})$ and fibrin deposits (F). Bacterial elongation (open arrows) and bacterial division (arrow) were also evident here. Another group of bacteria, some undergoing division (arrows), was observed in the extracellular location of a lesion on the second day (fig. 6), while a morphologically intact macrophage (M) was engaged in its antibacterial action. In fig. 7, a polymorph and a macrophage had infiltrated into an area of the white pulp on the second day, as identified by the prominence of intact lymphocytes (Ly). The polymorph appeared to be deteriorating while the macrophage was digesting its intracellular bacteria. It is unclear whether the elongated intact organism (arrow) was intracellular or extracellular.

\section{Discussion}

In murine salmonellosis, the pathogen proliferates rapidly in the organs of the reticuloendothelial system (RES). It has long been postulated that bacteria multiply within macrophages of host tissues and that acquired immunity is primarily cell-mediated (Collins, 1974). However, previous studies from this laboratory both in vitro (Hsu and Mayo, 1973; Marecki et al., 1975; Mayo et al., 1977) and in vivo (Guo et al., 1986a and $b$ ) have shown that virulent $S$. typhimurium cells are killed within polymorphs and macrophages of guinea- 


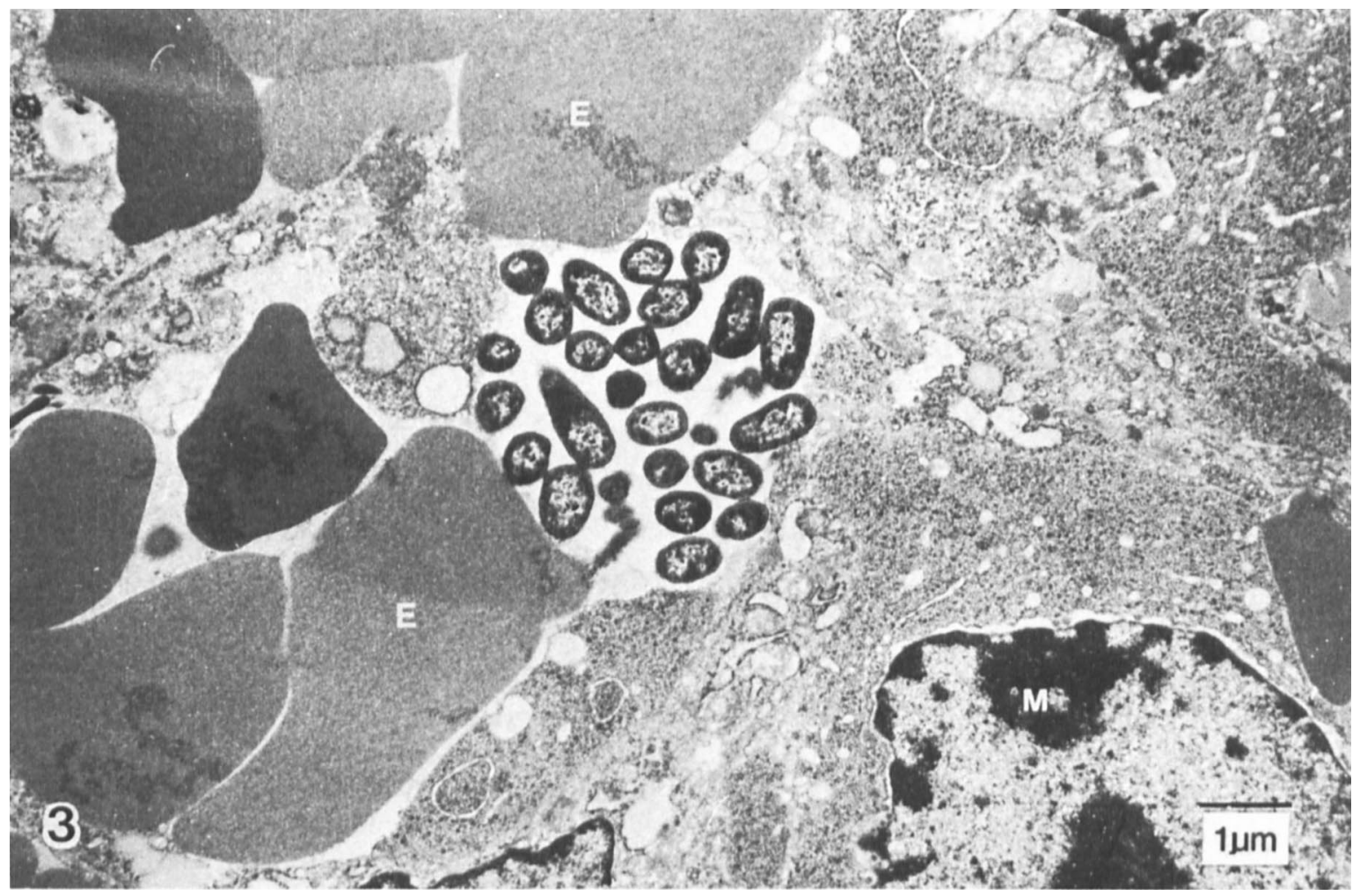

Fig. 3. Lumen of a sinusoid 3 days after infection. $M=$ nucleus of macrophage; $E=$ erythrocyte. Magnification: 11200.

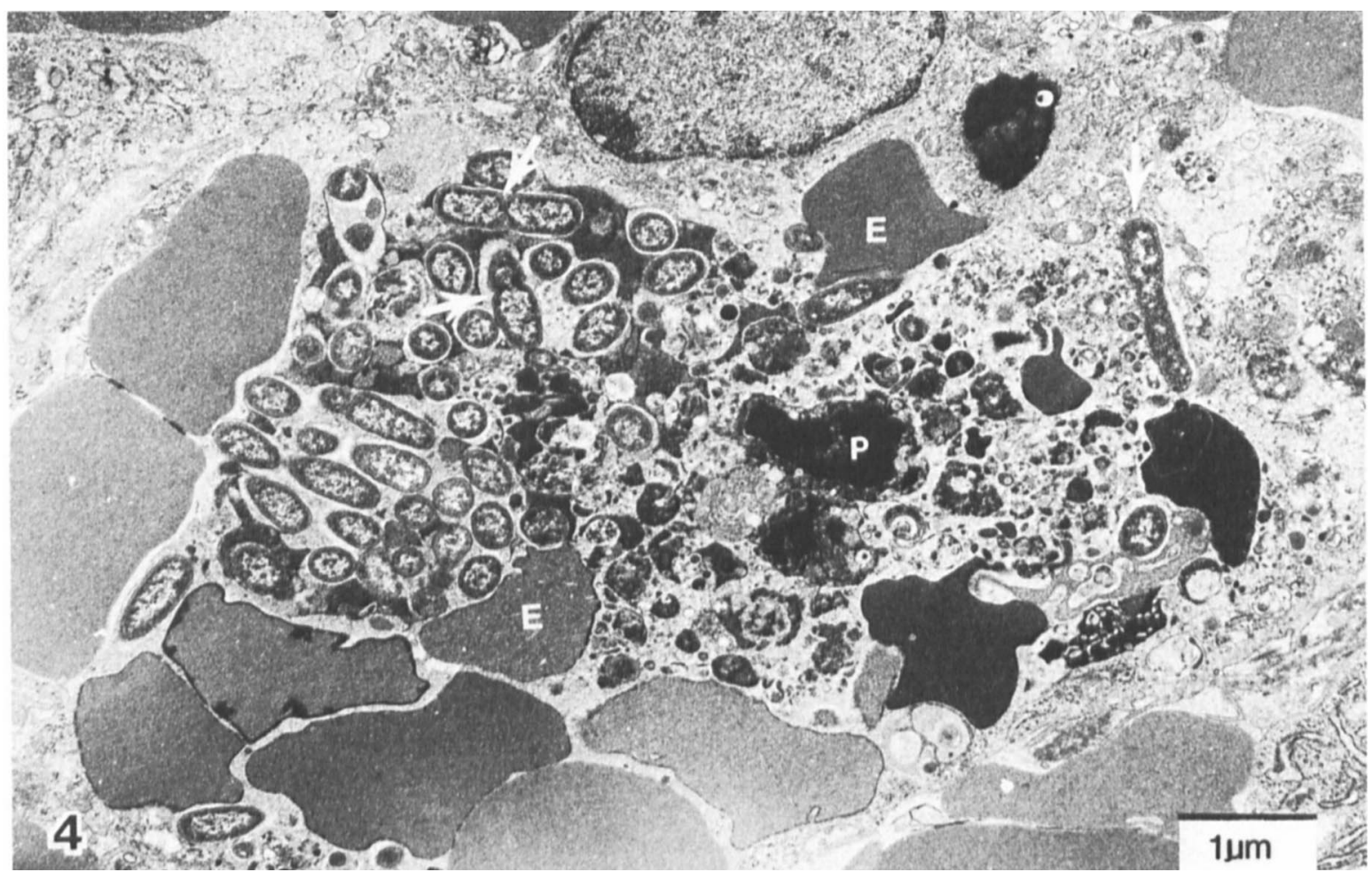

Fig. 4. A lesion in the red pulp of spleen 2 days after infection. $P=$ pyknotic nucleus of polymorph; $E=$ erythrocyte. Magnification: 14400 . 


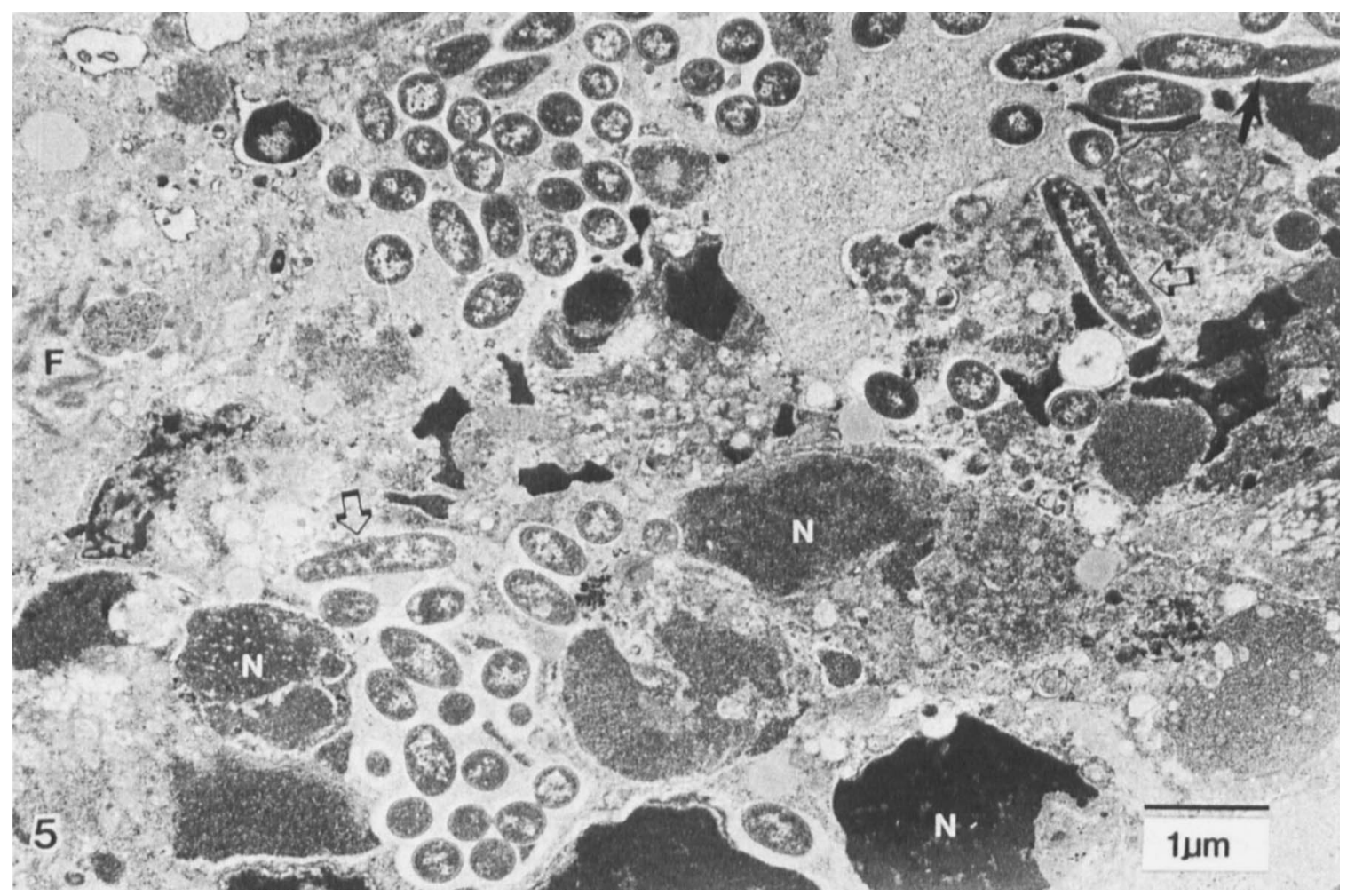

Fig. 5. A lesion in the spleen 3 days after infection. $\mathrm{N}=$ degenerating nucleus; $\mathrm{F}=$ fibrin. Magnification: 12400 .

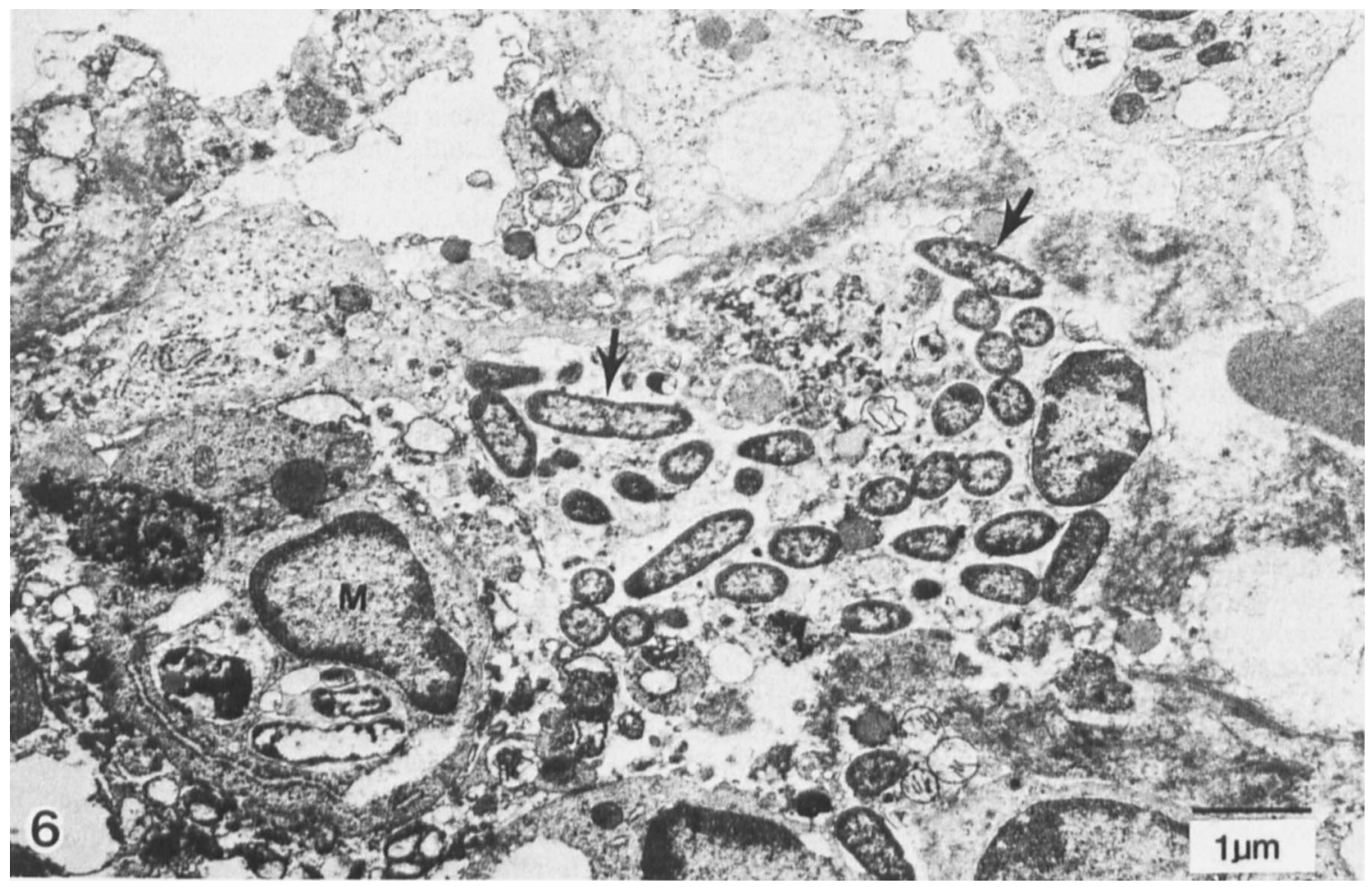

Fig. 6. A lesion in the spleen 2 days after infection. $M=$ nucleus of macrophage. Magnification: 14600 . 


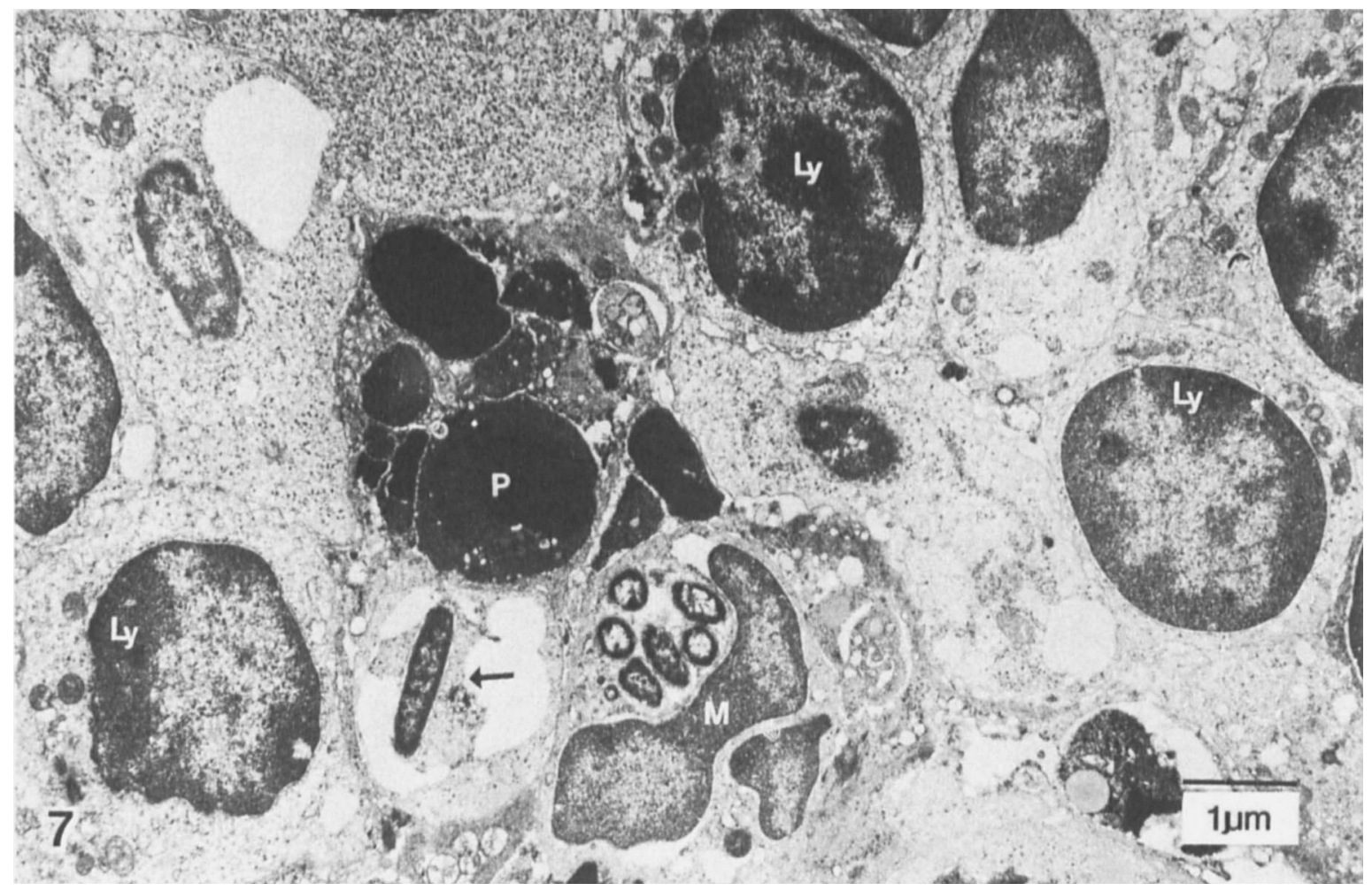

Fig. 7. Two adjacent phagocytes in the white pulp of spleen 2 days after infection. $\mathbf{M}=$ nucleus of macrophage; $\mathbf{P}=$ nucleus of polymorph; Ly= nucleus of lymphocyte. Magnification: 13500.

pigs and mice. Furthermore, histopathological studies (Nakoneczna and Hsu, 1980) also reveal that primary lesions in murine salmonellosis are characterised by abscess formation and are composed predominantly of polymorphs (not macrophages). Thus, it is essential to reconsider the assumption of the multiplication of virulent salmonellae within macrophages of the RES.

In the present investigation, mice were inoculated with a relatively large dose $\left(2 \times 10^{7} \mathrm{cfu}\right)$ of virulent salmonellae by the ip route to achieve a rapid dissemination of the pathogen throughout the RES. This was to facilitate the location of infected tissues by electronmicroscopy for the study of host-parasite interactions at the tissue level in the early stages of infection and before the onset of acquired immunity, which would otherwise complicate their interactions. That such a challenging dose did not compromise the host response to the infection is shown by the avid antibacterial actions of both the polymorphs and macrophages (figs. 1 and 2).

In electronmicroscopy, viability of bacteria in host tissues is based on morphological integrity.
Organisms appearing extracellularly (figs. 5 and 6 ) or within sinusoids (fig. 3) can be used as controls for comparative purpose. Consistent with preceding papers reporting on the intracellular destruction of salmonellae within inflammatory peritoneal cells (Guo et al., 1986a and $b$ ), an overwhelming majority of bacteria seen within polymorphs and macrophages at the site of infection in the spleen undergoes structural disintegration (figs. 1 and 2). This is indicative of the innate capacity of these phagocytes in the highly susceptible $\mathrm{C} 57 \mathrm{BL} / 6$ mice to kill salmonellae at the early stage of a primary infection. The polymorphs arrived obviously as a result of acute inflammation and some appeared capable of engulfing a large number of bacteria (fig. 1C). In rare incidents, morphologically intact bacteria could be seen within phagocytes. These might represent the result of intracellular survival or even multiplication. However, the presence of intact as well as disintegrating bacteria simultaneously within a phagolysosome (figs. 1C and 2B) would favour the interpretation that different stages of bacterial degeneration were present in one time frame. 
In the absence of any persuasive evidence of bacterial multiplication within phagocytes in $\mathrm{mu}-$ rine salmonellosis, it would be logical to predict that the proliferation of the pathogen in the spleen is occurring primarily outside these cells. Accumulations of bacteria were seen within sinusoids (fig. 3) and morphologically intact organisms, some dividing, were readily found among cellular debris in lesions (figs. 5 and 6). The pathogen invaded both the red pulp (fig. 4) as well as the white pulp (fig. 7). Collectively, both polymorphs and macrophages were responding to the infectious challenge promptly and effectively. For example, they infiltrated into the white pulp and ingested the invaders within two days post infection, as shown in fig. 7. The contention of intracellular killing and extracellular multiplication of salmonellae is best illustrated in fig. 6.

The present investigation is a descriptive rather than a quantitative study of the host-parasite interactions within infected tissues. With electronmicroscopy, only minute areas of tissues can be examined at a time and each tissue section consists of a plane across the host cells amounting to less than $1 \%$ of their spherical volume. Thus the procedure does not lend itself to statistical analysis for comparison of the numbers of intracellular versus extracellular bacteria within a given tissue specimen.

In essence, the electronmicrographs provide visual evidence in situ of events occurring in the infected tissues. The conclusion of intracellular destruction of salmonellae in vivo is in agreement not only with published data from this laboratory but also with results reported by others, as reviewed previously (Guo et al., 1986a). Recent papers by Briles et al. (1986) and van Dissel et al. (1985) also support the general observation of intracellular killing of salmonellae within macrophages. In a parallel study (Lin et al., in press), virulent salmonellae were also seen to be killed within polymorphs and macrophages in infected liver but to replicate in the extracellular locations within sinusoids and in early lesions, or within hepatocytes. Collectively, these experimental findings lend credence to our previous assertion that antibodies play a critical role in acquired immunity in murine salmonellosis by enhancing the ingestion of extracellular bacteria into a hostile intracellular environment of polymorphs and macrophages (Nakoneczna and Hsu, 1983; Hsu et al., 1985; Guo et al., 1986b). Solid protective immunity, on the other hand, depends on the synergic collaboration of both the humoral and cellular mechanisms of host immune response (Marecki et al., 1975; Nakonezna and Hsu, 1980 and 1983).

This study was supported by U.S. Public Health Service grant AI 19434 from the National Institute of Allergy cnd Infectious Diseases. Drs Xiu-mei Wang and Fa-rong Lin were visiting scientists from, respectively, the Department of Microbiology, Inner Mongolia Medical College, Huhehot, and Suzhou Medical College, Suzhou, People's Republic of China. The authors thank R. H. Freeman, Ethel T. Lovings and T. D. Lutz of the Electron Microscope Laboratory of the Department of Pathology, MCV/ VCU, for their technical assistance.

\section{REFERENCES}

Briles D E, Benjamin W, Posey B, Michalek S M, McGhee J R 1986 Independence of macrophage activation and expression of the alleles of the Ity (immunity to typhimurium) locus. Microbial Pathogenesis 1 : 33-41.

Collins F M 1974 Vaccines and cell-mediated immunity. Bacteriological Reviews 38 : 371-402.

Guo Y N, Hsu H S, Mumaw V R, Nakoneczna I 1986a Electronmicroscopy studies on the bactericidal action of inflammatory leukocytes in murine salmonellosis. Journal of Medical Microbiology 21: 151-159.

Guo Y N, Hsu H S, Mumaw V R, Nakoneczna I $1986 b$ Electronmicroscopy studies on the opsonic role of antiserum and the subsequent destruction of salmonellae within murine inflammatory leukocytes. Journal of Medical Microbiology, 22: 343-349.

Hsu H S, Mayo D R 1973 Interactions between macrophages of guinea pigs and salmonellae. III. Bactericidal action and cytophilic antibodies of macrophages of infected guinea pigs. Infection and Immunity 8: 165-172.

Hsu H S, Nakoneczna I, Guo Y N 1985 Histopathological evidence for protective immunity induced by sonicated Salmonella vaccine. Canadian Journal of Microbiology $\mathbf{3 1}$ : 54-61.

Hsu H S, Radcliffe A S 1968 Interactions between macrophages of guinea pigs and salmonellae. I. Fate of Salmonella typhimurium within macrophages of normal guinea pigs. Journal of Bacteriology 96: 191-197.

Lin F R, Wang X M, Hsu H S, Mumaw V R, Nakoneczna I Electron microscopic studies on the location of bacterial proliferation in the liver in murine salmonellosis. British Journal of Experimental Pathology (in press).

Marecki N M, Hsu H S, Mayo D R 1975 Cellular and humoral aspects of host resistance in murine salmonellosis. British Journal of Experimental Pathology 56: 231-243.

Mayo D R, Hsu H S, Lim F 1977 Interactions between salmonellae and macrophages of guinea pigs. IV. Relationship between migration inhibition and antibacterial action of macrophages. Infection and Immunity 18: 52-59.

Nakoneczna I, Hsu H S 1980 The comparative histopathology of primary and secondary lesions in murine salmonellosis. British Journal of Experimental Pathology 61 : 76-84

Nakoneczna I, Hsu H S 1983 Histopathological study of protective immunity against murine salmonellosis induced by killed vaccine. Infection and Immunity 39: 423-430.

van Dissel J T, Leijh P C J, van Furth R 1985 Differences in initial rate of intracellular killing of Salmonella typhimurium by resident peritoneal macrophages from various mouse strains. Journal of Immunology 134 : 3404-3410. 